\title{
Leadership and Management Profiles For The Internationalization of Iranian Higher Education
}

\author{
Fatemeh Hamidifar, ${ }^{\mathrm{a}, *}$ Kamaruzaman Yusoff, ${ }^{\mathrm{b}}$ Mansoureh Ebrahimi ${ }^{\mathrm{c}}$ \\ ${ }^{a}$ Faculty of Management, Islamic Azad University, Central Tehran Branch, Iran. \\ ${ }^{b}$ Faculty of Islamic Civilization, University Teknologi Malaysia, Johor, Malaysia. \\ ${ }^{c}$ Faculty of Islamic Civilization, University Teknologi Malaysia, Johor, Malaysia. \\ *Corresponding author:f.hamidifar@iauctb.ac.ir
}

\begin{abstract}
Article history
\end{abstract}
Received: 10/10/2016

Received in revised form:13/1/2017

Accepted: 04/03/2017

\begin{abstract}
Ongoing efforts to strengthen internationalization have increased the numbers of international students in institutions of higher learning. Such inflows will clearly place local institutions on par with many of their international counterparts. This paper explores the significance of higher education's internationalization with regard to leadership competencies and systems management. The objective is to examine a wide range of priorities that qualify a successful leader as well as an effective 'systems profile' for the internationalization of higher education and its profile on the internationalization of Iranian higher education. The authors analyze differences between leaders and managers as their core focus. Required criteria for effective leaders and team management are discussed with a specific view towards the internationalization of higher education. A qualitative approach applies and findings demonstrate how both leadership's and management's contributions and skills combine to accomplish the task. As a detailed synopsis, this paper provides prime incentive for future investigations of educational enterprises. It presents a substantiated framework for the systematic development of prudent internationalized institutions of higher education, particularly in Iran.
\end{abstract}

Keywords: Internationalization, Higher education, Leadership and Management. 


\subsection{INTRODUCTION}

The internationalization of higher education institutions is an issue of great interest to policymakers because of its pronounced influence on economic outcomes. Present internationalization efforts differ from the first half of the $20^{\text {th }}$ Century with regard to goals, activities, management and leadership (De Wit, 2012). The theme caps agendas for university leaders who desire internationalized institutions and global reach. Furthermore, despite its remaining vital to strategic objectives, internationalization of higher education has remained a muddled field and is variously interpreted because approaches traverses numerous national agendas. In practice, it encompasses a complex multifaceted process defined as follows:

The intentional process of integrating an international, intercultural or global dimension into the purpose, functions and delivery of post-secondary education, in order to enhance the quality of education and research for all students and staff, and to make a meaningful contribution to society" (Knight, 2003).

Hence, the field includes policies and practices undertaken by academic systems and institutions pertaining to the management of an increasingly globalized academic environment. We may consider Knight and De Wit (1997) the vanguard of research efforts in this arena and thank them for this definition. They were the first to consult relevant organizations and higher-ed institutions around the world and publish their findings.

By bringing students and teachers from different systems together, the internationalization of higher education [IoHE] creates heterogeneous milieus teeming with diversity. According to Marmolejo (2012), there are five major reasons for IoHE: (1) to improve student preparedness; (2) internationalize curricula; (3) enhance an institution's international profile; (4) bolster research and knowledge production; and (5) diversify faculty and staff. To the contrary, many institutions typically expect foreign students to assimilate within parochial environments (Kelly and Moogan, 2012). Moreover, the complexity of IoHE holds several challenges for policy makers such as equal access and quality assurance as well as impacts on national culture, governance and management (Edwards, 2007; OECD, 2008). Nonetheless, IoHE enables governments to develop university systems that hold a broader global framework and produce a skilled workforce with cosmopolitan awareness and multi-cultural competencies. In addition, such systems use public higher education funds to promote national participation in a universal knowledge-based economy that both contributes-to and benefits-from exchanges in educational services. IoHE also permits a nation to expand and elevate its countrywide and international profiles; leverage institutional strengths through strategic partnerships; enlarge the academic community and benchmark scholarly achievements; mobilize domestic intellectual resources; add significant contemporary learning outcomes to student experience; and develop stronger research groups.

For purposes of this paper, 'internationalization' refers to "the conscious effort to integrate and infuse international, intercultural and global dimensions into the ethos and outcomes of higher education. To be fully successful, it must involve active and responsible engagement of the academic community in global networks and partnerships" (NAFSA, 2008). This paper examines effective leadership and management of IoHE from the Iranian perspective as a study of 'responsiveness to change'. When and from where would Iranian higher education institutions obtain the readiness to make specific institutional responses to internationalization? What forces would involve in leading institutions to this readiness? Who would be the actors that articulated the need for such action? At the core, this study determines in what forms the leadership emerged for internationalization in Iranian institutions of higher education.

The author employed qualitative methods to assess IoHE in Iran and analyzed relevant literature with a focus on strategic approaches to leadership and management. We also included results from a Delphi Panel of Experts' exercise that focused on perceptions-of and suggestions for IoHE in Iran. 


\subsection{LEADERSHIP AND MANAGEMENT IN INTERNATIONAL HIGHER EDUCATION INSTITUTIONS}

In conducting this research, the researchers opted for qualitative or content-analysis approach. Given the contemporary nature of the topic under study, the researchers made use of primary sources such as newspaper articles as well as e-documents which highlight the present pondok-related and militant-related developments in Malaysia. Furthermore, other sources employed are those of secondary in nature and they include journals and books or works written on the issues concerned.

In going through the materials, there were a number of steps involved namely, data collection, categorisation of data, data analysis and finally, witing up or presentation of research findings. Since the phenomenon of radical or militant activities in general sense, is still very much present particularly in the surrounding Southeast Asian region, though in the case of Malaysia itself the situation is essentially under control, the researches have also outlined some recommendations and suggestions in order to provide hindsights to those agencies or parties that are related to the religious education system or pondok schools in the country on how to prevent possible spread of militant ideas particularly among citizens of the pondok schools, and eventually to avoid the occurence of militant acitivites involving either pondok students or teaching staff.

As the subject of IoHE is of great interest to policy makers, educationists and leaders, much research exists but very little has been published that actually describes a systematized approach to IoHE competencies that describe its leadership and management. Hence, there is need for a more precise understanding of 'success vs. failure' outcomes with regard to IoHE leadership and management.

Leadership and management are concepts that have been subjected to numerous definitions and interpretations (Kotter, 1990; Bush, 2007). Management is generally regarded as being orientated toward results, goals, control and problem solving. Leadership is generally more directed towards developing human relationships and social organizing. Although management and leadership are synonymously used within various contexts and milieus, they actually hold different influences and organizational impacts on the creation of executive action plans and individual performance outcomes, even though both roles similarly involve people in a work environment seeking to achieve organizational goals. People generally assume that persons in management positions are leaders; however, not all managers implement leadership skills. Both responsibility sets are essential for organizational success and are more clearly viewed as key roles that motivate human activity in a complementary manner (Middlehurst, 1999). Within the structure of an organization, leadership concerns itself more with doing the right thing while management is far more concerned about doing the thing correctly. Table 1 lists different functions for management vs. leadership in the academic context.

Table 1. Academic Management and Leadership Functions

\begin{tabular}{|c|c|c|}
\hline Area of operation & $\begin{array}{c}\text { Management } \\
\text { Produces Order and Consistency }\end{array}$ & $\begin{array}{c}\text { Leadership } \\
\text { Produces Change and Movement }\end{array}$ \\
\hline \multirow[t]{2}{*}{ Establish Agendas } & Planning and Budgeting & Establishing Direction \\
\hline & $\begin{array}{l}\text { Academic managers are skilled at } \\
\text { allocating necessary resources, } \\
\text { planning work and meeting deadlines. }\end{array}$ & $\begin{array}{l}\text { Academic leaders are highly trained } \\
\text { thinkers who are accustomed to } \\
\text { imaginative, long-term planning that } \\
\text { develops a vision for the future and } \\
\text { changes strategies to achieve that vision. }\end{array}$ \\
\hline \multirow[t]{2}{*}{ Employee Development } & Organizing and Staffing & Aligning People \\
\hline & $\begin{array}{l}\text { Academics managers prioritize self- } \\
\text { determination and individual expertise; } \\
\text { They have skills for independent } \\
\text { learning that enable them to create } \\
\text { effective processes. }\end{array}$ & $\begin{array}{l}\text { Academics leaders have a high degree of } \\
\text { intellectual curiosity; } \\
\text { They constructively criticize } \\
\text { unworkable procedures; } \\
\text { They enjoy collaboration and actively } \\
\text { find better solutions by consulting } \\
\text { colleagues and other institutions. }\end{array}$ \\
\hline Perform the Agenda & Control and Problem Solving & Motivation and Inspiration \\
\hline
\end{tabular}




\begin{tabular}{|c|l|l|}
\hline & $\begin{array}{l}\text { Academic managers enjoy the } \\
\text { intellectual challenge of linking theory } \\
\text { to practice and are often skilled at } \\
\text { project implementation and monitoring } \\
\text { for effectiveness. }\end{array}$ & $\begin{array}{l}\text { Typically, academic leaders are } \\
\text { intrinsically motivated, enthusiastic } \\
\text { about their subjects, committed to new } \\
\text { ways of understanding what is familiar, } \\
\text { and enjoy communicating their ideas to } \\
\text { others. }\end{array}$ \\
\hline Outcomes & $\begin{array}{l}\text { They take complex systems of people } \\
\text { and technology and consistently } \\
\text { predict short-term results }\end{array}$ & $\begin{array}{l}\text { They produce change and create } \\
\text { systems to effectively handle change }\end{array}$ \\
\hline $\begin{array}{l}\text { Academics managers self-regulate and } \\
\text { believe that consistently good results } \\
\text { are essential; } \\
\text { They also believe that over- } \\
\text { management and/or control by } \\
\text { stakeholders or others will diminish } \\
\text { rather than enhance quality. }\end{array}$ & $\begin{array}{l}\text { Academics leaders interpret the future } \\
\text { within a context of lasting qualities; } \\
\text { They are lifelong learners who take } \\
\text { change in stride; } \\
\text { As public intellectuals, they study } \\
\text { fundamental values and the feasibility of } \\
\text { political decisions. }\end{array}$ \\
\hline
\end{tabular}

Source: Adapted from Ramsden (1998): Learning to Lead in Higher Education, UK, Routledge.

Leaders require managers to make things actually get done and managers need leaders to keep pace with contemporary innovations (Middlehurst, 1999). In a university environment, the ideal leadership model is consensual and sensitive to different disciplinary cultures. Such leaders engender communal confidence about new directions and convince people to accept change and collaborate for its realization. Both management and leadership draw on the expertise and knowledge of the community to facilitate and support change rather than act as expert authorities that work in isolation to impose decisions (Olson et al. 2006).

Marquardt and Berger (2000), identified seven leadership competencies attributable to successful business executives in a globalized world: (i) possessing a global mindset; (ii) creating a global culture and vision; (iii) developing global human resources; (iv) leading global strategic planning; (v) creating global operations; (vi) fostering global structures; and (vii) promoting global learning. Robertson's (2005) study on university presidential leadership went on to determine rankings for these same competencies in the IoHE context by examining their levels of importance as perceived by American university presidents and trustees. Thus leadership for IoHE can be characterized as multifaceted, replete with competition, cooperation, alliances, shining examples, and individual excellence.

IoHE is a process of change that occurs culturally, educationally and socially in all domains (Kreber, 2009). Moreover, there are different approaches by which leaders bring about successful IoHE implementation (Stohl, 2007). Thus, leadership competencies are necessary to foster the campus-wide changes that achieve IoHE goals (Kishun, 2007). Srinivas (1995) considered seven characteristics as "components of a global mindset" that form the leadership competency framework that is required to meet IoHE challenges as organizations and individuals enter globalized settings. These attributes comprise positive attitutudes towards (i) acceptance of complexity and its contradictions; (ii) diversity consciousness and sensitivity; (iii) seeking opportunity in the midst of uncertainties; (iv) faith in organizational processes; (v) a focus on continual improvement; (vi) longterm perspective; and (vii) systems thinking. Rhinesmith (1996) identified six characteristics of a global mindset that describe effective internationalized management: competitiveness, complexity, adaptability, multicultural teamwork and diversity, uncertainty and expanding knowledge and skills.

Some scholars suggest that academic leadership is an art that embraces the impartation of imagination across conception, communication and engagement domains (Barnett, 2011; Bartell, 2003). Hence, a genuine IoHE leader can be characterized as multifaceted, competitive, cooperative, alliance prone and exemplary individuals who manifest excellence (Smithee, 2012). Leadership also involves responding to events/crises, initiating action, disseminating information and influencing thought. Barker (2002) suggested that leadership is hierarchical, as often assumed and personified as the proverbial captain of the ship; but he also includes numerous extrinsic and intrinsic dynamics as the ship navigates seas of change (Smithee, 2012). Therefore, IoHE leaders pilot the "process of social influence in which one person can enlist the aid and support of others 
in the accomplishment of a common task" (Chemers, 1997: p. 2). Furthermore, Devos (2003) argued that relatively little attention has been paid to strategies that bring about changes that promote quality internationalization.

Academic leadership has employed a variety of methods to promote IoHE. These include, for example, concepts and ideas, organizational changes, advocacy, research and publication, resources, policies, individual efforts, collaboration and competition (Smithee, 2012). IoHE leadership is best shared through collaboration and MOUs as well as by individual research. International higher education institutions are similar to other organizations and require a systematically balanced process of management and leadership with effective teaching processes as well as quality learning and research resources to achieve desired outcomes (Hamidifar, 2012).

\subsection{Effective IoHE Management and Leadership}

Internationalization is a complex phenomenon due to its multidimensional concepts and the evolution of meanings, elements, approaches and strategies in the field of higher education (Said et al. 2015; Hartman, 2011). Internationalisation's significance is growing with economic, political and social changes that drive an increasingly global knowledge economy and can be conceptualized at several levels, including world, regional, national, state, community, organization and individual. IoHE emerged as a strategic approach to cope with the forces of globalization that challenge higher education institutions and continue to develop rapidly as institutions move from associating international strategies for international student recruitment to the development of advanced internationalization agendas that incorporate recruitment, research collaboration and capacity-building. While many university leaders have always engaged in international recruitment and research, the expanding phenomenon assails governments with technological, political and demographic changes that compel university internationalization as a strategic goal. Examples of institutional strategies for internationalization are its contemporary inclusion in institutional mission statements and the financial support that is provided for students and curriculum internationalization (Childress, 2010).

Several studies suggest that IoHE opens numerous possibilities that can be exploited by effective leadership and management to produce wide-raging benefits for their institutions, students and faculties (Altbach \& Knight, 2007; Kishun, 2007; Knight, 2007). Effective IoHE leadership and management depend on setting direction and following suit by accordingly developing the organization, faculty members and staff. Nevertheless, institutions and leaders face an imposing array of management challenges involving costs and benefits that must be considered carefully (Eikin, et al. 2007). Universities can manage IoHE more effectively across four major domains: (i) learning the environment; (ii) developing a strategic plan; (iii) enhancing implementation; and (iv) monitoring and evaluating (Hernard et. al. 2012). In each domain, a number of different measures affect the entire experience; however, no single recipe fits all and each institution must choose its way forward.

\subsubsection{Learning the IoHE Environment}

First off, one must identify governmental objectives and relevant players, both domestic and foreign that bear interest to the institution. Objectives at the national level may include (i) the attraction of talent to the national system; (ii) international prestige of the national educational system; (iii) economic benefits; (iv) wider access to a larger variety of educational options and qualifications for domestic and international students; (v) political influence.

Secondly, one should identify governmental policy and regulatory elements that influence IoHE. These may include public financing; institutional autonomy and governance; accreditation processes and qualification frameworks - within and without higher education such as visa rules, intellectual property rights, planning regulations, employment regulations, legal arrangements, etc.

Thirdly, the institution must consider cultural contexts both domestically and in those nations of interest to the institution to identify likely challenges. These are likely to include student 
learning expectations and preparations to encounter students from different backgrounds and languages as well as their respective approaches-to and interpretations of ethical matters.

Fourthly, management must be prepared to analyze other factors that affect the IoHE environment such as geo-political and economic development trends; competition from other institutions and countries, as well as from other forms of learning; opportunities for collaboration via institutional networking and multinational enterprises; evolving technology; local environment and awareness.

\subsubsection{Development of an IoHE Strategic Plan}

A strategic plan is needed that addresses the following domains:

1. Clarify the institution's objectives by articulating how internationalization is expected to enhance the institution's major mission(s);

2. Select the most appropriate modes and forms of internationalization for the institution, taking into account both mission(s) and objectives and the environment affecting internationalisation;

3. Involve key stakeholders in active development to gain prized insights as to the best approach and strengthen their engagement and support for the chosen approach;

4. Develop a sustainable business model to support internationalization that accounts for the following:

a. expected benefits and costs over the medium term;

b. financing arrangements;

c. timing for roll out and phase implementation;

d. risk assessment;

e. ability to respond rapidly to new challenges in light of experience.

It is best to establish partnerships and join effective and relevant international networks. Principals should also verify that their institutions have the capabilities to support internationalization strategies and take concrete steps to fill identified gaps and be ready to adjust their approaches in light of delimitations. In addition, they must incorporate viable processes for monitoring and evaluation.

\subsubsection{Enhance Implementation}

IoHE has major implications that involve the logistics of physical and virtual mobility of students and faculty, information and knowledge, virtual access, and the sharing of policies and practices. Optimised implementation includes the following percepts: (a) learn from the experience of other institutions; (b) ensure broader institutional and departmental policies that are well-aligned with IoHE objectives; (c) effectively communicate the IoHE rationale to all stakeholders within and without the university; (d) establish an international office that offers support services for students and faculty and promotes the integration of international students within the institution's academic and social activities; (e) inject internationalization considerations into all aspects of teaching and learning across the institution and support the faculty's adaptation to new challenges that will inevitably arise; (f) use internationalization as a stimulus for deeper reflections on course content and more effective pedagogy to promote better learning outcomes for all students.

\subsubsection{Monitor and Evaluate}

It is vital to construct monitoring and evaluation procedures as part of the overall strategy to assess whether or not the chosen approach achieves its objectives and delivers promised benefits. Statistical indicators and surveys are needed to validate quality and effective progress (EgronPolak, 2011). Moreover, IoHE objectives should also be incorporated within the institution's broader quality assurance programs for teaching, learning, pastoral care and student satisfaction.

In order to implement an effective strategic plan for IoHE, keys to developing intercultural appreciation and an international workforce (Fielden, 2011) include the following: (a) governments should recognise the benefits of attracting skilled workers and revenue generation by fostering exchange and co-operation while providing cost-effective adjuncts to domestic education opportunities (OECD, 2008). Finally, a strategic plan's success is supported by the experiences of autonomous institutions with robust records for good governance and management who have provided assurances to students, employers and stakeholders (Knight, 2007). 
Governments advance IoHE by (i) steering internationalization policies (national strategy plans) that foster IoHE attractiveness and international competitiveness (global ranking); (ii) promoting internationalization within domestic institutions (e.g. by encouraging academic staff and student mobility); (iii) optimising internationalization strategies (e.g. establish a data canter to inform policy makers of advanced information).

An Iranian sponsored Delphi Panel of IoHE expert confirmed an encouraging overview that provides a viable outline for the future of IoHE in Iran through operative management and leadership platforms. "Leaders are not just individuals but could be organizations or associations and leadership for internationalization is a process of social influence in which one person can enlist the aid and support of others in the accomplishment of common task."

The panel identified major trends in current national planning for the future. These included:

1. The growing importance of internationalization at all levels encompassing a broad range of activities, strategic approaches and emerging national ambitions;

2. Increased institutional IoHE strategies and praxis including homogenization while recognizing limitations such as a sole focus on quantitative results;

3. Mounting funding challenges;

4. Increased privatization via revenue generation;

5. Effects of competitive pressure with an evident shift from 'cooperation only' to fierce rivalry;

6. Emerging regionalization with rising numbers of stakeholders and participants resulting in a storm of quantity vs. quality;

7. Insufficient data for comparative analysis and decision-making;

8. Notable emerging areas of focus such as the internationalization of curricula, transnational education and digital learning.

Iran's IoHE strategy began with the Government's Twenty-Year Vision program "to become an "economic and technological power" is at the heart of Iran's new understanding of Iran's foreign and security relations". The program's vision, mission and motivators were further reinforced by the Fifth Five-Year development plans "Creating instructional interaction with other countries and international institutions such as UNESCO and ISESCO". After the Joint Comprehensive Plan of Action (JCPOA, 2015), internationalization has progressed to national and institutional levels. For complete success, each institution's approach to IoHE-specific strategic responsiveness should be unique and crafted according respective legacies and aspirations. While no one model fits all, any comprehensive and integrated approach to IoHE requires a tailored strategy that is appropriately structured and supported. Leadership, as "the engine for change", is vital to the process (Kotter, 1996).

Academic rhetoric speaks more comprehensively of strategic IoHE policies but in reality praxis has far to go in most cases. Indeed, uneven degrees of accomplishment beg levelling as significant challenges in Iranian public and non-public universities raises revolutionary ensigns. These inevitable barriers are mainly linked to funding and regulatory constraints, but also to institutional issues of the lingua franca (English) and notions of academic engagement and reward. According to Green (2007), the most common barriers to IoHE are: (a) institutional leaders who do not see it as relevant; (b) a lack of institutional strategy; (c) non-systematized international programs and activities; (d) a lack of funding for the process; (e) a noninternationalized curriculum. Altbach and Knight (2007) warned us that several uncertainties affect the pace of internationalization such as terrorist threats, political realities and international insecurity. Additionally, there are weighty concerns over local applications of curricula and academic models that were/are designed in countries like America. Equally, there is the question of enablers such as technology, stronger and more equal collaboration, a greater focus on qualitative outcomes, the fostering of public-private initiatives, and greater confluence between education and research as well as between levels of education.

\subsection{Managing and Leading IoHE in Iran}

IoHE in Iran can be traced to the late 1800s when foreign lecturers were invited to Iran and students and faculty members were sent abroad for advanced studies and research (Hassan Pour, 
2014). Iran, a country of roughly 80 million people, must strengthen its national assets through international cooperation, especially as the nation's institutions of higher education teach more than four-million students annually (SCI, 2012). Hence, a reputable international profile for quality and high levels of student satisfaction and performance is essential. The Delphi Panel confirmed that most Iranian higher education strategies predominantly focused on short-term and/or long-term economic gain; recruitment and/or training of talented students and scholars; and gaining international visibility and repute. However, this implies that greater efforts are still needed to incorporate more comprehensive strategies towards achieving internationalized curricula and learning skills that further enhance levels of academic and research outcomes.

Effective approaches to IoHE have been outlined in a guiding document authored by the High Council of the Cultural Revolution that address the international viewpoint of the government and policy makers regarding expert activities in this domain.

\begin{abstract}
"Developing academic links with prestigious international canters and educational and research institutions through the establishment of joint universities, joint training courses, research projects and students exchanges with other countries with emphasis on the countries of the region and the Islamic world, especially in the fields of humanities, religious mystic and advanced sciences and the Islamic Republic of Iran's priority which is based on comprehensive scientific plan to the country's scientific development."
\end{abstract}

These include an accurate understanding of the concept of internationalization; flexibility and the avoidance of prejudice; and the prioritization of a clarified global environment for society in general. Even so, most Iranian institutions have not adjusted to the fast pace that attends internationalization regarding governance, management and financial obstacles. Such tardy adaptations tend toward the puzzlement that delays responsiveness in terms of vision, management, leadership and resources. Problems affecting the IoHE status quo are consequent to inadequate institutional management, insufficient investment of resources and finance, and academic deficiencies with respect to international exposure. The most important obstacle to Iran's IoHE is the divergence of stakeholder perspectives with respect to leadership and management in terms of direction setting and the organizational development of assets and human resources. Internationalization has been understood mainly as a kind of short-term student mobility from Islamic and Middle East counties, sometimes seen as international partnerships or joint projects. It is almost never perceived as the application of an international perspective to subjects taught or to research and intercultural communication on campus through processes of domestic internationalization approaches. Outcomes of the Delphi Panel strongly suggest that the 'scarcity of internationality' marks a weakness in Iranian higher education, research and innovation, and this is in addition to a lack of institutional autonomy and insufficient sources of income. Iran lacks qualified foreign students, researchers and teachers and there is very little in the way of funding for foreign research and development. Moreover, Iran's attractiveness as a work environment for industrial production, high-end technology and top-notch experts is wanting. On the other hand, the good reputation enjoyed by our education and research systems abroad proves there is a great deal of untapped opportunities for IoHE. This is precisely why a national strategy for IoHE was included in the government's Twenty-Year Vision plan and a recently issued sixth 'five-year development plan' (2016-2021), which emphasizes increasing international mobility for students, teachers and researchers.

Nonetheless, Iran's concept of internationalization remains alien for many nationals and few have attempted to utilize the concept of internationalization to improve teaching and learning quality at the national level. The Delphi Panel clearly demonstrated an awareness of issues related to IoHE governance and management, but so far the Education Ministry has been unable to propose or enforce changes beyond limited achievements. However, many debaters have measured the value of IoHE's relationship to business and industry. It seems the most important challenge to IoHE in Iran is neither financial nor organizational, but rather the degree of cultural change that is required. At the moment, rigid sets of habit and thought regarding social organization are incapable of responding to rapid change and are still to be transformed (Duderstadt, 2000). 
Globally, internationalization implies a major paradigm shift wherever it is applied; hence, it is important to provide broader implications for cultural changes as well as for the massification of higher education associated with changes in the law; shifts in organisational models; and changes in institutional management. At the same time what has not changed must also be considered as having equal influence on the process of IoHE in Iran. To achieve the paradigm shift, higher education institutions must progressively consider global change factors and be able to exploit the opportunities so afforded. Here is where creative and innovative individuals provide platforms for success, especially when higher education reform grants these institutions greater responsibility and operational freedom. The Ministry of Science, Research and Technology (for non-medical universities), and the Ministry of Health and Medical Education (for medical schools) should commit their respective domains to the provision of operational frameworks that increasingly enable active operations within highly valued global networks of educational and research collaboration. Premium approaches to international educational marketing and collegial exchanges include branch campuses with programs designed for international students; sound English-medium programs and degrees; exchange programs for students, staff and scholars; internationalization of the curricula; cross-border collaborative arrangements and agreements; and setting up subsidiary colleges. Many ideas have been tried with lessons learned and lessons in progress. Numerous attributions concerning international eminence indicate a conscientious focus on the specific goal of reaching premier educational excellence through the creation of values that engage stakeholders and create sustainable opportunities for advancement in multiple domains.

\subsection{CONCLUSIONS AND RECOMMENDATIONS}

During the second decade of the $21^{\text {st }}$ century it became clear that the wealth of nations and mankind's well-being depend on ideas and knowledge. Knowledge is critical to processes of economic growth and social progress for which institutions of higher learning are vital. IoHE involves numerous strategies, initiatives, processes and stakeholders across a universal network that is becoming far greater than the sum of its parts (Olson et al. 2006). It is also generally understood that a university's response to economic, social and cultural changes that are directly related to globalisation is a multidimensional concept. Hence, IoHE is a natural result of the internationalization of global material and intellectual development that meets the evolving demand for economic development. Both development and competition necessitate joint efforts to cultivate high-level professionals who embrace collaborative scientific research that tackles key problem areas that reach far beyond the limits of any one country. Major components of IoHE include universal competition for the recruitment of talented academics and international students; international branch campus development; exchange programs for students, staff and scholars; the internationalization of curricula as well as regional and international research and education partnerships (De Wit et al. 2015). Mostly for economic and political reasons, the levels of IoHE so far achieved remain globally unbalanced. Some efforts have focused on countries in specific regions such as the Bologna Process in Europe, but institutions in developed countries tend to benefit more from recruiting the best students worldwide because their prestige grants them exceptional positions. Even so, institutions in developing countries attract foreign universities and faculty and sedulously improve the quality of their education programs. Countries like China, Malaysia and India have developed strategies to attract students and even export educational programs and institutions throughout Asia. The Middle East is also avidly internationalizing. For example, Saudi Arabia has established a new private venture with the University of Arizona and Harvard plans a branch campus in the United Arab Emirates (Observatory on Borderless Higher Education, 2010).

To the contrary however, some academics consider IoHE a dangerous process. Prakash and Stuchul (2004) challenged the assumption that higher education's transformation into a universally wholesome human right is a good thing. They used the metaphor of 'fast food' to describe the West's obsession with global education as a component of their "One World" fantasy, traceable as far back as the parable of the Good Samaritan. The authors (2004) soundly criticized the West's "One World" social construction as a so-called "right path" because it is defined by a set of universal moral obligations rooted in Western cultural myths. This Western 
theory of 'knowing the right path' for us all was previously used to justify both colonization and Westernization of 'other' cultures (Prakash and Stuchul, 2004).

Nevertheless, IoHE is not a goal in itself but rather a means to bring about civilized/cultural excellence that should not become solely focused on monetized reasoning (Knight, 2003). If provided with effective leadership and governance, the future of IoHE in Iran is potentially bright. Albeit, positive developments can only occur if stakeholders and participants maintain open dialogues regarding benefits, means, opportunities and obstacles in this on-going and inevitable dynamic. We must also face challenges of increasingly profound social, economic (mounting financial crises) and cultural issues involving unfavourable demographic trends, immigration, ethnic and religious tensions. While these threats surely exist, they also foster an awareness of IoHE's importance and the development of qualified, meaningful responses. In this respect, quality is comprehensively international in scope and inclusive of all educational aspects such as teaching, learning, curricula, research, ICT, infrastructure, facilities, human capital development and talent management, governance and leadership. Moreover, the need to view quality from a universal perspective is pressing and demands responses-from and to international stakeholders. Hence, IoHE quality controls should aim to create value for international stakeholders that are aligned with international standards through clear frameworks calling for strategic plans focused on quality leadership and governance.

\subsection{FUTURE SCENARIOS FOR RESEARCH}

Since internationalization is relatively new, as are strategic approaches used by higher education institutional management in response to rapid global changes, there is obvious need for additional research. Multiple avenues are open to IoHE investigations, especially for leadership and management; hence, the suggestions presented here are far from exhaustive.

No doubt IoHE will remain a central dynamo and its research can only help identify effective institutional and independent stratagems. By 2025, Australian experts expect nearly 15 million students will be studying 'abroad' worldwide, compared to the current two million (AIU, 2009). Consequently, it becomes imperative to understand international trends, especially in America, as it has been the leading host country for decades although its foreign enrollments have declined in recent years. Moreover, there is need to examine IoHE implications for leadership and, by extension, to review leadership's core functions institutions adapt to new teaching, learning, research and enterprise modalities in Iran. In an increasingly multi-cultural national context, and in relation to universities that are progressively internationalizing their staffing and operations' cadre, the theme of 'cross-cultural leadership' waxes with greater significance. Finally, as the relationship between state and its higher education armada sail with global tides, studies in various interactive levels and attributes of leadership, management and governance will become crucial. As worldwide IoHE constantly reshapes global campuses, the study of its processes and the knowledge gained will likely guarantee competitiveness and the survival of postsecondary institutions.

\section{References}

Altbach, P. G. (2010). “The Asian Higher Education Century?” International Higher Education, 59.

Altbach, P. G. and Knight, J. (2007). "The Internationalization of Higher Education: Motivations and Realities." Journal of Studies in International Education, 11(3/4): 296-297, 299.

Barnett, R. (2011). Being a University. Routledge.

Bartell, M. (2003). "Internationalization of Universities: a university culture-based framework." Higher Education, 45 (43-70).

Chemers, Martin M. (1997). An Integrative Theory of Leadership. Mahwah, NJ: Erlbaum Associates.

Childress, L. K. (2010). The Twenty-first Century University: Developing Faculty Engagement in Internationalization. New York: Peter Lang Publishing.

De Wit, H. (2012). The Changing Role of Leadership in International Education, University World News, 225, www.universityworldnews.com. 
De Wit, H., Hunter, F., Howard, Egron-Polka, E. (2015). Internationalization of Higher Education. doi: 10.2861/444393, http://www.europarl.europa.eu/studies

Devos, A. (2003). "Academic standards, internationalization, and the discursive construction of the international student." Higher Education Research and Development, 22(2): 155-166.

Edwards, J. (2007). "Challenges and opportunities for the internationalization of higher education in the coming decade: Planned and opportunistic initiatives in American institutions." Journal of Studies in International Education, 11(3/4): 373-381.

Egron-Polak, E. (2011). "Monitoring internationalization of higher education." International Higher Education, 63 (Spring) : 2 pp. 2-33, Boston College Center for International Higher Education,.

Eikin, G., Farnsworth, J. \& Tempier, A. (2008). "Strategy and the internationalization of universities." International Journal of Educational Management, 22(3): 239-250.

Fielden, J. (2011). Getting to Grips with Internationalisation: Resources for UK Higher Education Institutions. Leadership Foundation for Higher Education: London.

Green, M. F. (2007). "Internationalizing community colleges: Barriers and Strategies." New Directions for Community Colleges, 138: 15-24.

Hamidifar, F. (2012). "Effective Leadership in Iranian Higher Education." SFIMAR Research Review, 7(2): 13-19.

Hartman, E. (ed.) (2011). Internationalization of Higher Education: Toward a new research agenda in critical higher education studies. NY: Routledge.

Hassan Pour, F. (2014). Design of Higher Education Learning Spaces in Iran; From the Qajar Period to the Present Time. Snapshots International Symposium on Learning Spaces, University of Melbourne (June). doi:10.13140/2.1.2169.5040

Hénard, F., Diamond, L. \& Roseveare, D. (2012). Approaches to internationalization and their implications for strategic management and institutional practice: A guide for higher education Institutions. Paris: OECD.

http://isacmsrt.ir/files/site1/pages/barnamepanjom.pdf

http://isacmsrt.ir/files/site1/pages/barnamepanjom.pdf

Institute of International Education (2009). Higher education on the move: New developments in global mobility. Institute of International Education Washington: DC.

Jackson, J. (2008). "Globalization, Internationalization, and short-term stays abroad." International Journal of Intercultural Relations, 32: 349-358

Joint Comprehensive Plan of Action. (2015). Retrieved from: https://eeas.europa.eu/statementseeas/docs/iran_agreement/iran_joint-comprehensive-plan-of-action_en.pdf

Kelly, P. and Y. Moogan (2012). "Culture shock and higher education performance: implications for teaching." Higher Education Quarterly, 66(1): 24-46, doi: 10.1111/j.1468-2273.2011.00505.x.

Kishun, R. (2007). "The internationalization of higher education in South Africa: Progress and challenges." Journal of Studies in International Education, 11(3-4): 455-469.

Knight, J. \& De Wit, H. (eds.) (1997). Internationalization of higher education in Asia Pacific countries. Amsterdam: European Association for International Education.

Knight, J. (2003). "Updating the definition of internationalization." International Higher Education pp. $2-3$.

Knight, J. (2005). "Internationalization of Higher Education: New Directions, New Challenges." IAU Global Survey Report, available on request: 1au2@unesco.org

Knight, J. (2007). "Internationalization Brings Important Benefits as Well as Risks." International Higher Education 46 (Winter). 
Knight, J. (2008). "The internationalization of higher education: complexities and realities." In D. Teferra \& J. Knight (eds.), Higher education in Africa: The international dimension (pp. 1-43), Boston: AAU/CIHE.

Kouzes, J.M. and Posner, B.Z. (2007). The Leadership Challenge. San Francisco, CA: Josssy-Bass.

Kreber, C. (2009). "Different perspectives on internationalization in higher education." New Directions for Teaching and Learning, 118: 1-14.

Marmolejo, F. (2012). "Internationalization of higher education: the good, the bad, and the unexpected." Chronicle of Higher Education (October).

Marquardt, M.J. \& Berger, N.0. (2000). Global leaders for the 21st century. Albany: State University of New York Press.

NAFSA: Association of International Educators. (May 2008). Internationalization of Higher Education: A working definition of internationalization. NAFSA "s Internationalization Task Force (Jan.Mar. 2008: McCarthy J., Altbach, P., Dellow, D., Drake-Gobbo, L., Stevenson, S. Sutton, S \& Wu, Y., accessed 16 Aug. 2008: http://www.nafsa.org//Document//nafsas_contribution.pdf

OECD (2008). Tertiary Education for the Knowledge Society (Vols. 1 \& 2). OECD Publishing. doi: $10.1787 / 9789264046535$-en

Olson, C.L., Green, M.F. and Hill, B.A. (2006). A Handbook for Advancing Comprehensive Internationalization: What Institutions Can Do and What Students Should Learn. Washington: American Council on Education.

Prakash, M.S. \& Stuchul, D. (2004). "McEducation Marginalized: Multiverse of learning-living in grassroots commons." Educational Studies, 36(1): 58-73.

Rhinesmith, S.H. (1996). A Manager's Guide to Globalization: Six Skills for Success in a Changing World (2nd Ed.). NY, NY: McGraw-Hill.

Robertson, L. B. (2005). American higher education in a global society: A study of presidential leadership. Ph.D. Thesis, Kent State University Graduate School of Education. UMI number: 3180715.

Smithee, M.B. (2012). "Finding Leadership for the Internationalization of U.S. Higher Education." Journal of International Education and Leadership, 2(1): http://www.jielusa.org/home

Srinivas, K.M. (1995). "Globalization of Business \& the Third World: challenge of expanding the mindsets." Journal of Management Development, 14(3): 26-49. doi:10.1108/02621719510078957, http://dx.doi.org/10.1108/02621719510078957

Statistical Center of Iran (2012). Iran Statistical Yearbook, Population. Tehran.

Stohl, M. (2007). "We have met the enemy and he is us: The role of the faculty in the internationalization of higher education in the coming decade." Journal of Studies in International Education, 11(3-4): 359-372. 